\title{
Resting ECG Changes
}

National Cancer Institute

\section{Source}

National Cancer Institute. Resting ECG Changes. NCI Thesaurus. Code C119218.

Any new or worsening ST or T wave changes present in two or more contiguous leads

that occur when a patient is experiencing neither physical nor chemical stressors. 